\title{
Verbal Auditory Agnosia Developed after Unilateral Temporal Lobe Infarction
}

\author{
Jeong-Bae Jeon ${ }^{1}$, Min-Chae Jeon ${ }^{1}$, and Dong-Hee Lee ${ }^{1,2}$ iD \\ ${ }^{1}$ Department of Otorhinolaryngology-Head and Neck Surgery, College of Medicine, The Catholic University of Korea, Seoul; and \\ ${ }^{2}$ Department of Otorhinolaryngology-Head and Neck Surgery, Uijeongbu St. Mary's Hospital, College of Medicine, \\ The Catholic University of Korea, Uijeongbu, Korea
}

일측 측두엽 뇌경색 이후 발생한 언어청각실인증 1 예

전정배 $^{1} \cdot$ 전민채 ${ }^{1} \cdot$ 이동희 ${ }^{1,2}$

가톨릭대학교 의과대학 이비인후과학교실, ${ }^{1}$ 가톨릭대학교 의과대학 의정부성모병원 이비인후과학교실 ${ }^{2}$

\author{
Received April 24, 2020 \\ Revised September 14, 2020 \\ Accepted September 15, 2020 \\ Address for correspondence \\ Dong-Hee Lee, MD, PhD \\ Department of Otolaryngology- \\ Head and Neck Surgery, \\ Uijeongbu St. Mary's Hospital, \\ College of Medicine, \\ The Catholic University of Korea, \\ 271 Cheonbo-ro, \\ Uijeongbu 11765 , Korea \\ Tel $+82-31-820-3564$ \\ Fax $+82-31-847-0038$ \\ E-mail1eedh0814@catholic.ac.kr
}

Stroke results in sudden loss of function related to its damaged portion. When this occurs in temporal lobe, the function of hearing and listening may be affected, although receptive language processing is affected while hearing perception is relatively spared. This is called as "central deafness." It has been known that hearing ability is seldom impaired in the case of temporal lobe stroke except in the case of bilateral lesions. However, we experienced a 72-year-old, right-handed woman who presented with both sudden hearing difficulty due to unilateral temporal lobe infarctions after suddenly not being able to respond to any verbal questions except environmental sounds. Pure-tone audiometry showed both flat sensorineural hearing loss of mild degree in both ears but she could not understand any verbal sound. Brain MRI demonstrated extensive ischemic infarcts in the left temporal lobes involving primary auditory cortex. She was diagnosed as verbal auditory agnosia and has received speech-language therapy. Korean J Otorhinolaryngol-Head Neck Surg 2021;64(4):277-84

Key Words Auditory agnosia · Cerebral infarction · Primary auditory cortex · Sudden hearing loss.

\section{서 론}

중추성 난청은 청각 중추로 청각 정보를 전달하는 중추 청 각 신경계(central auditory nervous system, CANS)의 손상 에서 기인한다. CANS 병변에 따라서 임상양상이 다른데, 와 우핵 병변인 경우에는 뇌병변 동측에 일측성 난청이 발생하 는 반면에 뇌간, 간뇌 혹은 청각피질 병변은 난청보다는 소리 의 인지 혹은 분별의 장애를 주로 유발할 뿐 일측성 전농은 드물게 유발한다. ${ }^{1)}$ 중추성 난청은 언어적, 비언어적 소리에 대 한 반응 정도와 언어의 이해 정도에 따라 피질난청(cortical

This is an Open Access article distributed under the terms of the Creative Commons Attribution Non-Commercial License (https://creativecommons.org/licenses/by-nc/4.0) which permits unrestricted non-commercial use, distribution, and reproduction in any medium, provided the original work is properly cited. deafness), 언어청각실인증(verbal auditory agnosia) 혹은 순 수어농(pure word deafness), 비언어청각실인증(non-verbal auditory agnosia), 전반청각실인증(generalized auditory agnosia)으로 구분한다(Table 1). ${ }^{2,3)}$

현재까지 상부 CANS의 뇌졸중으로 인한 중추성 난청의 국내 보고가 수차례 있었으남-6) Mun 등ㄱㅇㅣ 일측성 측두엽 뇌출혈로 인한 양측 난청 증례를 보고하였을 뿐, 일측성 측 두엽 뇌경색으로 인한 언어청각실인증이 발생한 국내 증례 보고는 없었다. 국외 사례들 ${ }^{8-14)}$ 에서도 일측성 측두엽 병변으 로 인한 중추성 난청은 Maffei 등 ${ }^{12)}$ 과 Deng 등 ${ }^{13)}$ 의 보고뿐 이다. 이에 저자들은 74세 여자 환자에서 일측성 중대뇌동맥 영역의 좌측 측두엽 뇌경색 병변 이후 발생한 언어청각실인 증을 경험하였기에 문헌 고찰과 함께 보고하는 바이다. 
Table 1. Summary of central auditory nervous system disorders

\begin{tabular}{|c|c|c|c|c|}
\hline & Cortical deafness & $\begin{array}{c}\text { Verbal auditory } \\
\text { agnosia }\end{array}$ & $\begin{array}{c}\text { Non-verbal auditory } \\
\text { agnosia }\end{array}$ & $\begin{array}{c}\text { Generalized auditory } \\
\text { agnosia }\end{array}$ \\
\hline Linguistic auditory comprehension & Impaired & Impaired & Normal & Impaired \\
\hline Non-linguistic auditory comprehension & Impaired & Normal & Impaired & Impaired \\
\hline Hearing sensitivity & Impaired & Normal & Normal & Normal \\
\hline Spontaneous speech & Normal & Normal & Normal & Normal \\
\hline Reading comprehension & Normal & Normal & Normal & Normal \\
\hline Written language & Normal & Normal & Normal & Normal \\
\hline
\end{tabular}

Verbal auditory agnosia is also known as (pure) word deafness. Non-verbal auditory agnosia is called as auditory sound agnosia or environmental sound agnosia ${ }^{2,3)}$

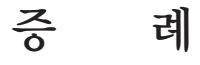

75세 오른손잡이 여자 환자가 내원 5시간 전부터 지남력의 저하, 물건 조작 능력의 저하와 동반되어 양측 청각장애를 주소로 응급실로 내원하였다. 과거력상 환자는 고혈압, 당뇨, 부정맥, 주요우울장애를 기저질환이 있었고, 2002년 우측 성 대용종으로 미세후두수술, 2008년 L5-S1 추간판 절제술을 받았고 2012년 타병원에서 우측 전교통동맥 동맥류 파열로 결찰술(clipping)을 받았으나, 이후 신경학적으로 남은 후유 증은 없었고 청능이나 언어 의사소통 능력에 문제없이 지냈 다. 내원 시 신경학적 진찰에서 의식은 기면상태였고 뇌신경, 운동기능은 모두 정상 소견이었다. 환자는 검사자의 질문에 제대로 대답하지 못하였고, 검사자가 하는 말을 전혀 알아듣 지 못하여 명령 이행이나 따라 말하기도 전혀 하지 못하였으 나, 손뼉이나 전화벨소리와 같은 비언어적 소리에는 반응이 있었다. National Institute of Health Stroke Scale은 9점으 로 중등도 수준이었고 글라스고우 혼수척도(Glasgow Coma Scale)는 눈뜨기반응 4점, 언어반응 3점, 운동반응 6점이었 다. 이전에는 일상생활 수행에 필요한 전반적인 기억력이나 운동기능에는 문제가 없었고 성격이 변화되거나 길을 찾는 일, 충동 조절 능력 등에서도 변화가 없었다고 하였다.

내원 당일 시행한 뇌자기공명영상에서 일차청각피질을 포 함하는 좌측 측두엽에서 급성 뇌경색이 확인되었다(Fig. 1). 이후 입원하여 시행한 뇌혈관조영술에서는 좌측 중대뇌동맥 의 폐색이 확인되었으나 조영술 도중에 저절로 재개통되었고, 이전에 시술받았던 우측 전교통동맥 동맥류 결찰술 부위는 온전하였으나 좌측 중대뇌동맥 이분지에서 새롭게 동맥류가 확인되었다(Fig. 2). 이에 환자는 신경외과로 입원하여 항응 고요법 및 재교통 시술을 포함한 급성 뇌경색 치료를 진행하 였고, 입원 후에도 13 일째 지속되는 양측 청각장애에 대해 본과로 전과되었다.

발병 5일에 시행한 이비인후과 문진상 환자의 의식 수준은 명료하였고 말소리를 전혀 분별하지 못하는 청각장애를 호
소하였고 이명, 현훈은 호소하지 않았다. 환자의 구강조음기 관의 구조상 특이사항 없었고, 기능상 움직임에 있어서 마비 성 말장애의 증상은 관찰되지 않았다. 환자가 읽기와 말하기 수행은 잘 하였고 자음정확도 $100 \%$ 로서 유창성에도 문제가 없었으나 검사자의 질문에 대한 듣기 이해도가 떨어졌다. 한 국판 웨스턴 실어증 검사(Korean version of Western Aphasia Battery)에서 실어증 지수(aphasia quotient)는 22.0 (13\%ile)이었다.

이학적 검사상 이개, 외이도, 고막에는 이상소견이 없이 정 상이었고 자발 및 주시 안진, 두진후 안진 등의 전정기능 이 상소견은 보이지 않았다. 발병 9일에 시행한 청성뇌간반응검 사상 청력역치는 우측 $70 \mathrm{dBnHL}$, 좌측 $60 \mathrm{dBnHL}$ 로 측정 되었고 1-5파의 잠복기 및 파간 및 양이간 잠복기 차이는 모 두 정상범위였다(Fig. $3 \mathrm{~A}$ ). 발병 13 일에 시행한 순음청력검사 상 우측 $35 \mathrm{~dB} \mathrm{HL}$, 좌측 $30 \mathrm{~dB} \mathrm{HL}$ 의 감각신경성 난청 소 견이 확인되었고(Fig. $4 \mathrm{~A}$ ) 어음청력검사를 시도하였으나 환 자는 제시음을 소리로서 감지를 하였으나 제시되는 어음 자 체를 인지하지 못하여 어음청력검사는 진행이 불가하였다. 청성지속반응검사상 청력역치는 우측 $56 \mathrm{dBeHL}$, 좌측 51 $\mathrm{dBeHL}$ 로 측정되었다(Fig. $3 \mathrm{~B}$ ).

좌측 측두엽의 급성 뇌경색으로 인한 양측 돌발성 중추성 난청으로 진단하고 항응고요법 및 재교통 시술을 포함한 급 성 뇌경색 치료를 받았으나 청능 및 의사소통에 호전이 없어 서 5일간 프레드니솔론 $50 \mathrm{mg}$ /일을 투약하고 이후 5일간 감 량하는 일정의 고용량 스테로이드 요법을 적용하였다. 퇴원 전에 시행한 순음청력검사상 우측 $21 \mathrm{~dB} \mathrm{HL}$, 좌측 $19 \mathrm{~dB}$ $\mathrm{HL}$ 로 약간의 호전소견을 보였고 환자도 일부 말소리를 알아 듣는다는 주관적 증상 호전을 보였으나 여전히 제시되는 어 음 자체를 인지하지 못하여 어음청력검사는 불가하였다. 하 지만 발병 1.5 달 후 외래에서 시행한 순음청력검사상 우측 $40 \mathrm{~dB}$ HL, 좌측 $30 \mathrm{~dB}$ HL로 호전없는 소견을 보였고(Fig. $4 \mathrm{~B})$, 여전히 제시되는 어음 자체를 인지하지 못하고 의사소 통의 어려움을 호소하여 언어청각재활치료를 시행 중이다. 


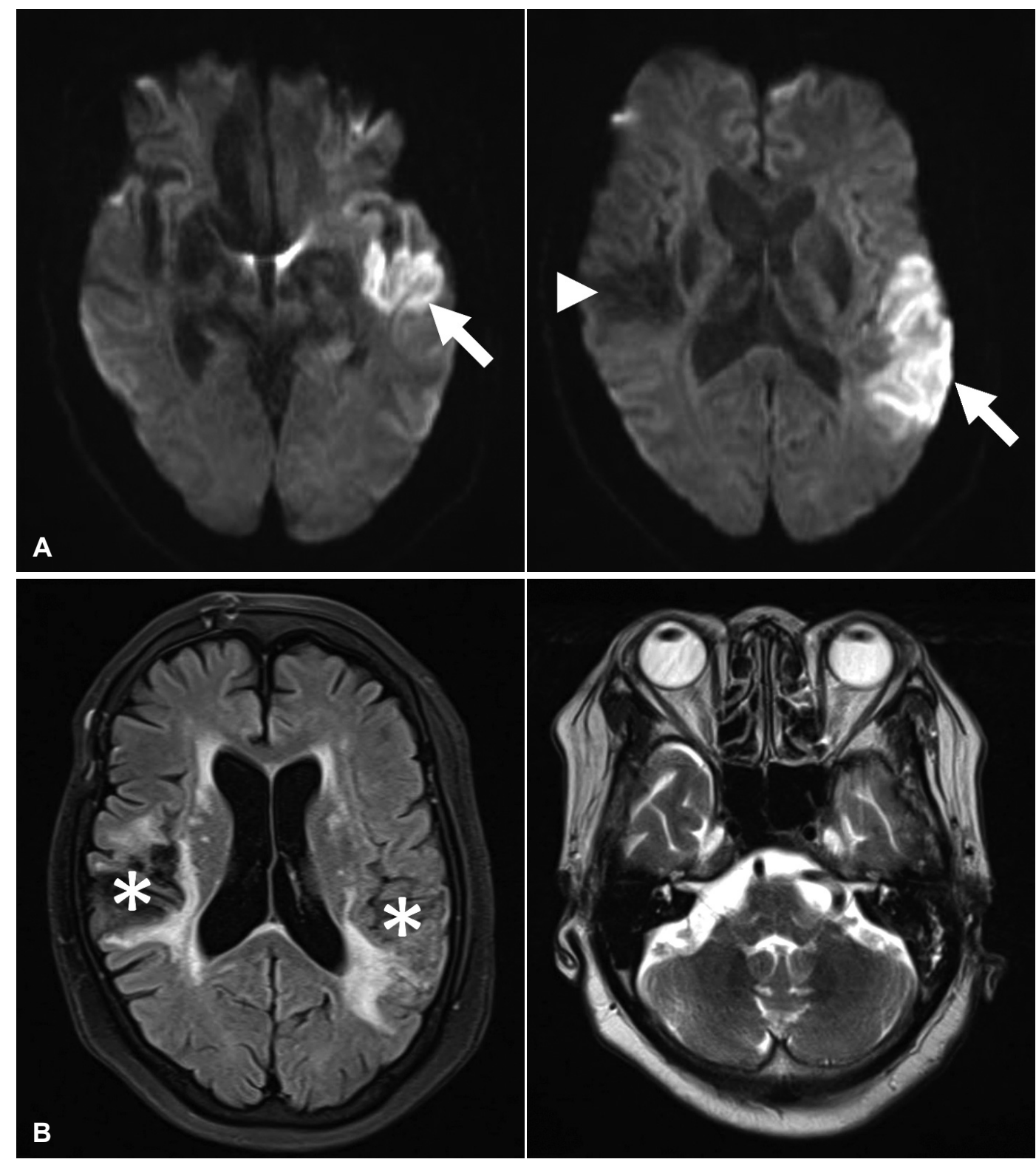

Fig. 1. MRI. Diffusion-weighted images of initial MRI show patchy high signal intensity (arrows) in left parieto-temporal lobe, suggesting acute infarction. Old infarction with encephalomalacia (arrowhead) is also shown in right temporal lobe (A). T2-weighted images of MRI followed 3 months later shows encephalomalacia (asterisks) in both temporal lobes but does not find out any retrocochlear lesion (B).

발병 3개월 때 추가로 발견된 좌측 중대뇌동맥 이분지 동맥 류에 대한 코일 색전술을 받았다(Fig. 2B). 발병 6개월인 현재 환자는 기억력 및 인지장애, 정서장애 혹은 운동기능이상 등 을 포함한 신경학적 후유증 없이 청능과 언어 의사소통 능력 에만 장애를 갖고 있다.

\section{고 찰}

허혈성 및 출혈성 뇌졸중 등에 의한 중추성 난청이 임상적 으로 잘 인식되지 못하거나 드물게 보고되는 이유는 와우핵,
하구, 내슬상체 등의 CANS는 다중으로 혈액을 공급받아서 심각한 기능손상이 드물고, 와우핵 이상의 상위 CANS는 양 측 귀로부터 청각 정보를 받는 잉여성(redundancy)이 있어서 일측 뇌병변에서는 증상 발현이 미미하여 발견되기 어려우 며, CANS의 병변으로 인한 청각장애는 단순한 난청이나 농 이 아닌 다양하고 섬세한 청각장애를 초래하는데, 이러한 미 세한 청각기능의 이상은 통상의 순음청력검사만으로는 알아 낼 수 없기 때문이다. ${ }^{15)}$ 또한 뇌출혈이나 뇌경색 환자들 대부 분은 청각장애 이외에 다른 신경학적 손상으로 인한 영향이 압도적이고, 신경과나 신경외과로 입원하여 치료를 받기에 

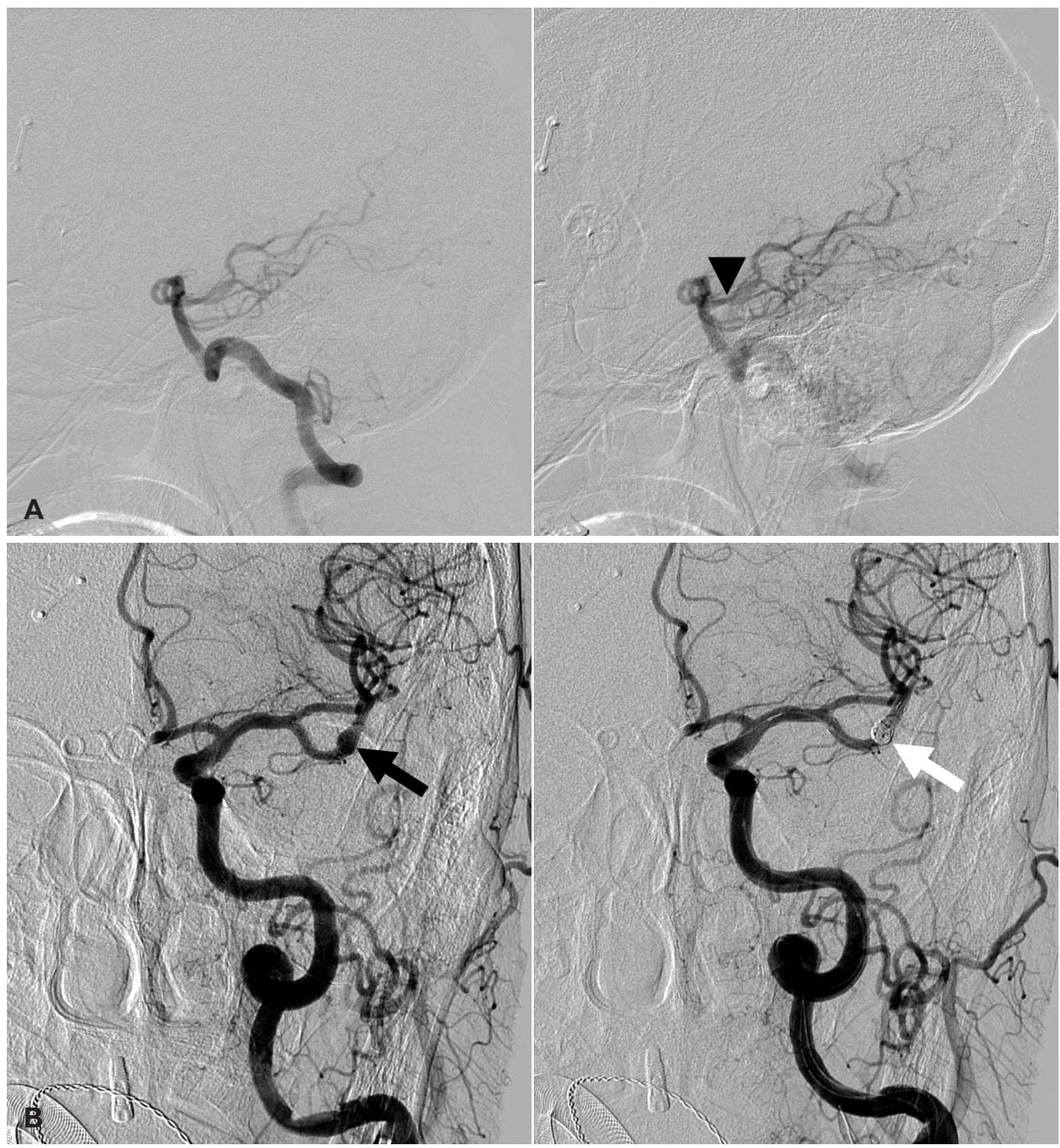

Fig. 2. Angiography. Lateral view shows that left middle cerebral artery (arrowhead) was occluded initially but recanalized spontaneously during angiography (A). Anteroposterior view confirms that left middle cerebral artery M2 aneurysm (black arrow) was successfully filled with coil (white arrow) (B).

청각장애가 간과될 수 있다.

CANS 병변 중에서 뇌간 병변의 경우 청각장애만 단독으 로 나타나는 경우는 드문데 양측성 대칭성 고음역 난청과 더 불어 어음명료도의 저하가 특징이고 특히 청성뇌간반응검사 에서 제1-3파 잠복기 차이가 지연되는 특징적인 소견을 보인 다. 청각피질 병변의 경우 청각장애 양상이 매우 다양하고 환 청과 같은 증상을 곧잘 동반하는데, 순음청력검사상 청력역 치의 저하가 미미하고 심지어 통상적인 어음청력검사에서는 어음명료도가 정상으로 나올 수 있으므로 이분청취 검사, 편 이저잉여성어음 검사, 양이상호작용 검사, 시간적처리 검사와 같은 중추청각처리 능력을 검사해야 한다. 청각피질 병변에 서는 어음명료도 저하가 청신경 자체의 병변인 경우보다 덜
하기 때문에 어음명료도가 정상범위이기도 하지만, 대부분의 중추성 난청의 경우 통상적인 어음청력검사에서는 환자가 검사 설명 혹은 제시음 자체를 이해하지 못하여 '검사불가'인 경우를 검사자가 ‘어음명료도 $=0 \%$ ’로 오인하여 결과지를 내기 도 하므로 어음명료도 결과를 판독할 때 주의해야 한다. 본 증례의 순음청력검사, 청성뇌간반응검사, 청성지속반응검사 결과를 감안할 때 본 환자는 원인불명의 경도 감각신경성난 청을 기왕력으로 갖고 있었고, 이 경도 난청은 측두엽 뇌경색 으로 인한 것이 아닌 것으로 추정된다. 하지만 이번 측두엽 뇌경색으로 인하여 중추성 난청이 발생하여 어음 제시음을 인지하지 못하는 중추성 난청이 추가로 발생한 것으로 해석 하였다. 


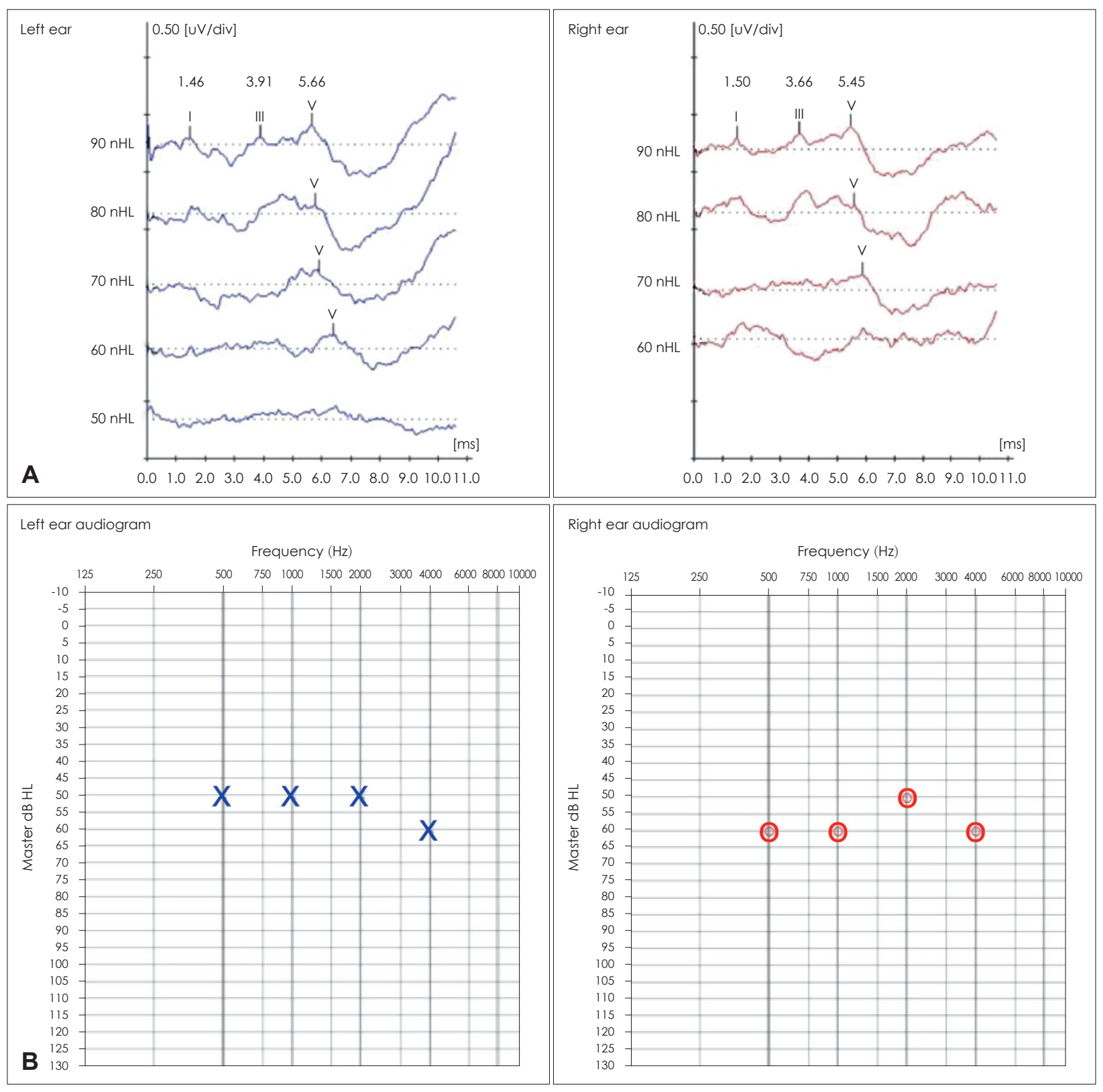

Fig. 3. Results of electrophysiologic auditory tests. (A) Click auditory brainstem response test (headphones, low pass filter=100 $\mathrm{Hz}$, high pass filter $=3000 \mathrm{~Hz}$, averaging=1024). Interwave intervals of $1-3$ waves $=2.17 \mathrm{msec}, 3-5$ waves $=1.79 \mathrm{msec}$ and $1-5$ waves $=3.96 \mathrm{msec}$ in right ear; $1-3$ waves $=2.46 \mathrm{msec}, 3-5$ waves $=1.75 \mathrm{msec}$ and $1-5$ waves $=4.21 \mathrm{msec}$ in left ear. (B) Auditory steady-state response test.

상부 CANS 병변에 의한 청각장애는 언어적 및 비언어적 소리에 대한 반응의 정도에 따라 크게 4가지로 구분되는데 (Table 1), ${ }^{2,3}$ 본 환자의 경우 지남력 및 물건 조작 능력의 저하 와 동반된 양측 청각장애를 보였고 비언어적 소리를 잘 인지 하였으며 순음청력검사에서 청각민감도(hearing sensitivity) 가 경도 난청이라는 점에서 언어청각실인증으로 진단할 수 있었다. 또한 본 증례에서는 읽기, 쓰기가 잘 보존되어 있다 는 측면에서 감각실어증과 구분되었다. 저자들의 문헌 검색상 일측성 측두엽 병변으로 인한 중추성 난청은 Maffei 등ㄹㄱㄱㅘ
Deng 등 ${ }^{13)}$ 의 보고뿐이고 피질난청이 아니고 언어청각실인증 의 임상양상으로 나타난 것은 Maffei 등 ${ }^{12}$ 과 Silva 등 ${ }^{14}$ 의 보 고뿐이다(Table 2). ${ }^{2-14)}$

Mun 등, ${ }^{7)}$ Maffei 등, ${ }^{12)}$ Deng 등 ${ }^{13)}$ 의 보고 이외의 증례들은 사실상 양측 병변으로 인한 청각장애로 볼 수 있는데, 선천 적 혹은 과거에 이미 반대측 뇌병변이 있었기 때문이다. 만약 본 증례를 Mun 등ㄱㅇㅢ 해석대로 일측 측두엽 뇌경색에서 기 인한 언어청각실인증 및 양측 돌발성 청능 저하로 가정한다 면 그 기전을 설명하기 쉽지 않지만 일측성 피질하 병변에서 

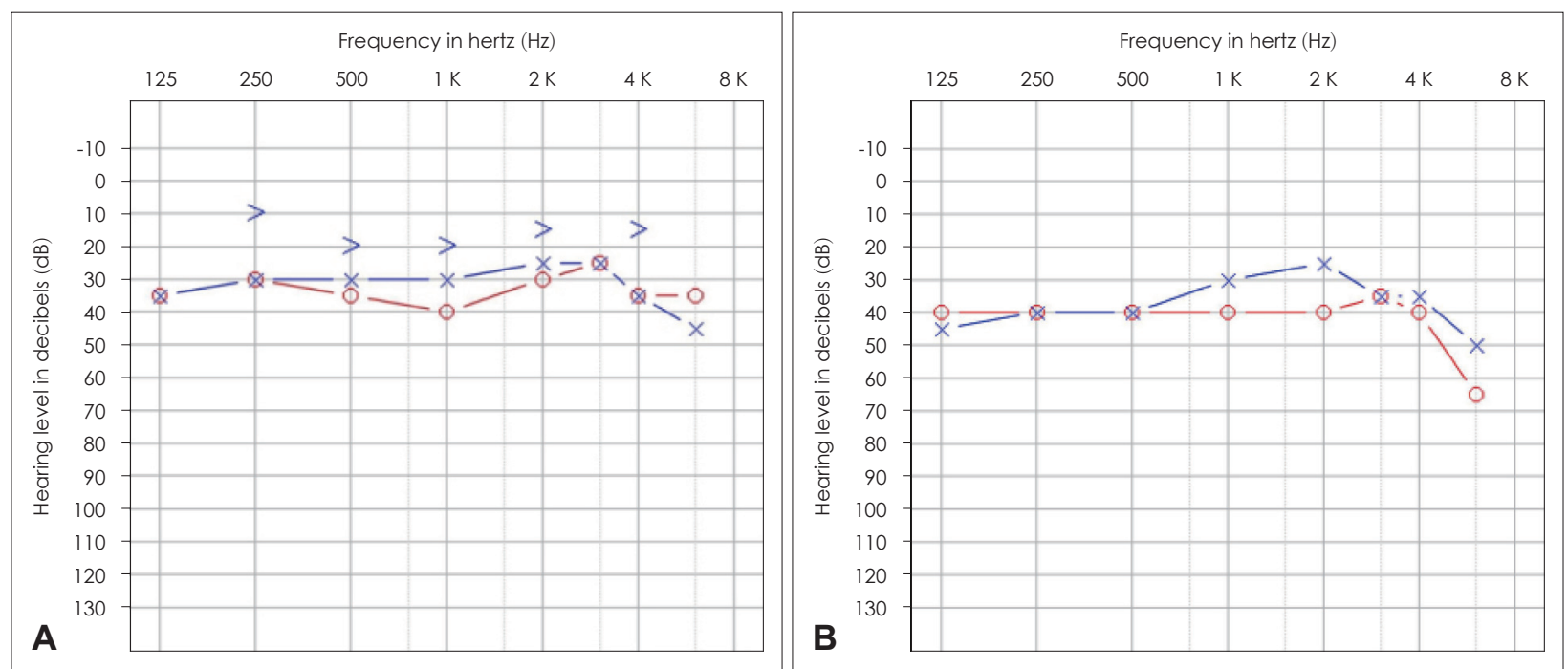

Fig. 4. Pure-tone audiogram. Initial audiogram (A) and audiogram of 1.5 months after the onset $(B)$. They show flat sensorineural hearing loss of mild degree in both ears.

실인증과 같은 청각장애가 발생하는 기전으로 좌측 뇌반구 가 언어 우세성을 지니며 좌측 언어적 소리에 대한 청각 정보 에서 우세성을 지닌다는 점을 감안할 때 청각이나 언어에 우 세한 좌측 측두엽이 우·좌측 어느 쪽으로부터 청각 정보를 받지 못하면 실인증이 발생할 수 있다고 유추할 수 있다. ${ }^{2}$ 두 번째 가정은 이전에 있던 CANS 병변에 더불어 이번에 새로 이 반대측에 발생한 일측성 뇌병변으로 인하여 궁극적으로 양측성 CANS 병변이 발생했다고 해석하는 것인데, 이런 해 석이 지배적인 이유는 소리 자극이 와우 신경을 통해 뇌간으 로 들어간 후 양측 청각경로를 경유하여 상행하여 위에서 언 급한 CANS 잉여성으로 인하여 뇌간 상부 또는 측두엽의 일 측 병변으로 인해 양측 청각장애가 발생하는 경우는 드물다 는 사실에 기인한다. ${ }^{8)}$ 따라서 $\operatorname{Suh}$ 등 $^{2}$ 의 해석대로 이번에 생 긴 뇌병변은 일측성이지만 과거에 우측 전교통동맥 동맥류 파열로 인한 뇌경색이 반대측에 이미 있었고 따라서 과거에 있던 뇌경색이 비우세성 뇌반구에 발생하여 무증상으로 지 내다가 이번에 우세성을 지닌 일차청각중추인 좌측 측두엽에 뇌경색이 생기면서 양측으로 증상이 발생한 것으로 본 증례 의 기전을 설명하는 것이 타당하다고 저자들은 생각한다."

돌발성 중추성 난청 혹은 청능 저하를 놓치지 않으려면 반 드시 이신경학적 검사를 시행하고 청각을 단순히 청력역치 혹은 청각민감도의 저하로 보기보다는 청각 정보처리 차원에 서 청각적 지각에 대한 부분을 검사해야 하는데, 최근 Koohi 등 ${ }^{15)}$ 은 고령자 청력 장애 검사(Hearing Handicap Inventory for the Elderly)와 같은 구조화된 설문지로 중추성 난청의 선별검사가 가능하다고 제시하였다.

본 증례에서는 좌측 측두엽의 급성 뇌경색에 대한 항응고
요법 및 재교통 시술 이후에 지속되는 청각장애에 대하여 고 용량 스테로이드 요법을 적용하였다. 이는 일부 보고 ${ }^{6}$ 에서 고 용량 스테로이드를 투여하였던 점을 근거로 환자, 보호자와 상의하여 시도한 것으로서, 아직까지 중추성 난청에서 고용 량 스테로이드 요법의 치료효과에 대한 근거는 없고 중추성 난청의 치료는 원인이 되는 뇌병변에 대한 치료, 그리고 언어 청각재활치료로 구성된다는 것을 임상의들은 숙지해야할 것 이다.

중추성 난청의 경우 보고가 드물고 이비인후과적 경과 관 찰이나 중추청각처리능력 검사의 미비로 인하여 그 예후가 정확하게 알려져 있지 않으나 일반적으로는 청각장애의 예후 는 뇌병변의 위치와 초기 증상의 정도에 따라 다르지만 전반 적으로 좋지 않은 것으로 보고되고 있다. ${ }^{3.9)}$ 뇌병변의 원인 자 체가 뇌혈관 연축처럼 가역적인 경우에는 청각장애의 완전회 복이 가능하고, 양측 측두엽 심부의 뇌출혈이 아닌 이차부종 에 의한 피질난청은 부종이 호전되면 청력이 회복되는 경우 도 보고되었다. 하지만 양측 측두엽병변, CANS의 양측 병변 이나 순수어농의 경우에는 영구적일 가능성이 있으며, 운동 능력 저하와 실어증을 동반한 경우에도 예후가 불량하고, 운 동능력 저하없이 난청과 실어증을 모두 동반한 경우 예후는 중간 정도로 보고되고 있으며, 양측 양측 청각방사섬유가 완 전히 차단될 경우 청각장애가 심하고 오래 지속된다고 알려 져 있다.")

본 저자들은 일측성으로 발생한 중대뇌동맥의 폐쇄로 인 해 발생한 좌측 측두엽의 급성 뇌경색에 동반하여 발생한 양 측 청각인지능력이 저하된 언어청각실인증 사례를 경험하였 기에 문헌 고찰과 함께 보고하는 바이다. 
Verbal Agnosia by Temporal Infarct I Jeon JB, et al.

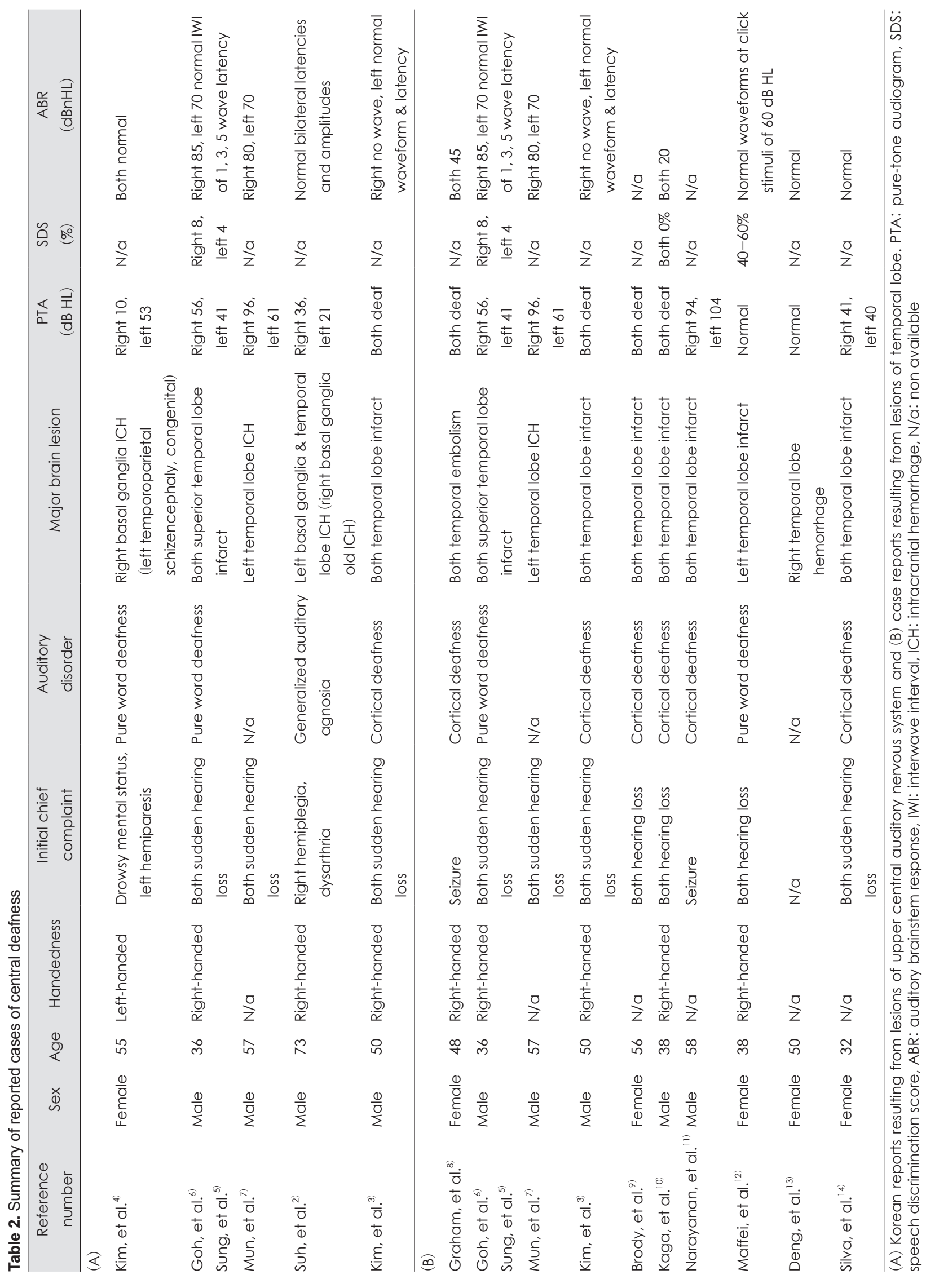




\section{Acknowledgments}

Ethics committee approval was received from Institutional Review Board (IRB) of Uijeongbu St. Mary's Hospital, College of Medicine, The Catholic University of Korea (IRB No. UC20ZISE0061). Written informed consent was not obtained because this was a retrospective case report.

\section{Author Contribution}

Conceptualization: Dong-Hee Lee. Data curation: Jeong-Bae Jeon. Investigation: Jeong-Bae Jeon, Min-Chae Jeon. Supervision: Dong-Hee Lee. Visualization: Jeong-Bae Jeon, Dong-Hee Lee. Writing — original draft: Jeong-Bae Jeon. Writing - review \& editing: all authors.

\section{ORCID}

Dong-Hee Lee https://orcid.org/0000-0002-0401-1183

\section{REFERENCES}

1) Henkel CK. The Auditory System. In: Haines DE, Mihailoff GA, editors. Fundamental Neuroscience for Basic and Clinical Applications. 5th ed. Amsterdam: Elsevier;2018. p.317.

2) Suh H, Shin YI, Kim SY, Kim SH, Chang JH, Shin YB, et al. A case of generalized auditory agnosia with unilateral subcortical brain lesion. Ann Rehabil Med 2012;36(6):866-70.

3) Kim SW, Kim J, Nam HS, Heo JH, Kim YD. Cortical deafness caused by bilateral acute middle cerebral artery infarctions. J Korean Neurol Assoc 2012;30(3):203-6.

4) Kim BJ, Park MK, Park KW, Lee DH. A case of pure word deafness. J Korean Neurol Assoc 1995;13(2):353-61.

5) Sung SM, Kim SH, Park KH. A case of pure word deafness. J Korean Neurol Assoc 1997;15(2):377-81.
6) Goh EK, Kim JH, Baek MJ, Chon KM. A case of sudden central deafness. Korean J Audiol 1997;1(1):106-9.

7) Mun SK, Hong YH, Kang SH, Hwang SN. A case of temporal intracerebral hemorrhage that presented with sudden bilateral hearing loss as the initial symptom. J Korean Neurosurg Soc 2010; 48(5):438-40.

8) Graham J, Greenwood R, Lecky B. Cortical deafness--a case report and review of the literature. J Neurol Sci 1980;48(1):35-49.

9) Brody RM, Nicholas BD, Wolf MJ, Marcinkevich PB, Artz GJ. Cortical deafness: A case report and review of the literature. Otol Neurotol 2013;34(7):1226-9.

10) Kaga K, Shinjo Y, Enomoto C, Shindo M. A case of cortical deafness and loss of vestibular and somatosensory sensations caused by cerebrovascular lesions in bilateral primary auditory cortices, auditory radiations, and postcentral gyruses - complete loss of hearing despite normal DPOAE and ABR. Acta Otolaryngol 2015;135(4):389-94.

11) Narayanan S, Majeed KA, Subramaniam G, Narayanan A, Navaf KM. A case of cortical deafness due to bilateral heschl gyrus infarct. Case Rep Med 2017;2017:6816748.

12) Maffei C, Capasso R, Cazzolli G, Colosimo C, Dell'Acqua F, Piludu F, et al. Pure word deafness following left temporal damage: Behavioral and neuroanatomical evidence from a new case. Cortex 2017:97:240-254.

13) Deng Y, Shi J, Zhang M, Qi X. Clinical characteristics of cerebral hemorrhage with bilateral sudden deafness as the first symptom. Neurol Sci 2021;42(1):141-50

14) Silva J, Sousa M, Mestre S, Nzwalo I, Nzwalo H. Cortical deafness of following bilateral temporal lobe stroke. J Stroke Cerebrovasc Dis 2020;29(7):104827.

15) Koohi N, Vickers DA, Utoomprurkporn N, Werring DJ, Bamiou DE. A hearing screening protocol for stroke patients: An exploratory study. Front Neurol 2019;10:842. 